\title{
Acid-Sensing Properties in Rat Gastric Sensory Neurons from Normal and Ulcerated Stomach
}

\author{
Takeshi Sugiura, ${ }^{1,2}$ Khoa Dang, ${ }^{1}$ Kenneth Lamb, ${ }^{1}$ Klaus Bielefeldt, ${ }^{3}$ and G. F. Gebhart ${ }^{1}$ \\ ${ }^{1}$ Department of Pharmacology, Carver College of Medicine, The University of Iowa, Iowa City, Iowa 52242, ${ }^{2}$ Department of Anesthesiology and Medical \\ Crisis Management, Nagoya City University Graduate School of Medical Sciences, Nagoya 467-8601, Japan, and ${ }^{3}$ Division of Gastroenterology, Department \\ of Internal Medicine, University of Pittsburgh, Pittsburgh, Pennsylvania 15261
}

Gastric acid contributes to dyspeptic symptoms, including abdominal pain, in patients with disorders of the proximal gastrointestinal tract. To examine the molecular sensor(s) of gastric acid chemonociception, we characterized acid-elicited currents in dorsal root ganglion (DRG) and nodose ganglion (NG) neurons that innervate the stomach and examined their modulation after induction of gastric ulcers. A fluorescent dye (DiI) was injected into the stomach wall to retrogradely label gastric sensory neurons. After 1-2 weeks, gastric ulcers were induced by $45 \mathrm{~s}$ of luminal exposure of the stomach to $60 \%$ acetic acid injected into a clamped area of the distal stomach; control animals received saline. In whole-cell voltage-clamp recordings, all gastric DRG neurons and 55\% of NG neurons exhibited transient, amiloride-sensitive, acid-sensing ion-channel (ASIC) currents. In the remaining 45\% of NG neurons, protons activated a slow, sustained current that was attenuated by the transient receptor potential vanilloid subtype 1 antagonist, capsazepine. The kinetics and proton sensitivity of amiloride-sensitive ASIC currents differed between NG and DRG neurons. NG neurons had a lower proton sensitivity and faster kinetics, suggesting expression of specific subtypes of ASICs in the vagal and splanchnic innervation of the stomach. Effects of $\mathrm{Zn}^{2+}$ and $N, N, N^{\prime}, N^{\prime}$-tetrakis-(2-pyridylmethyl)-ethylenediamine on acid-elicited currents suggest contributions of ASIC1a and ASIC2a subunits. Gastric ulcers altered the properties of acid-elicited currents by increasing $\mathrm{pH}$ sensitivity and current density and changing current kinetics in gastric DRG neurons. The distinct properties of NG and DRG neurons and their modulation after injury suggest differential contributions of vagal and spinal afferent neurons to chemosensation and chemonociception.

Key words: visceral hypersensitivity; proton; DRG; ASIC; TRPV1; DiI; gastric chemonociception; TPEN

\section{Introduction}

Dyspepsia, defined as pain or discomfort located in the upper abdomen and altered by food intake, affects $\sim 25 \%$ of adults in the United States. In the majority of patients, no structural or biochemical abnormality can be found. It is now generally accepted that changes in visceral sensation in the form of visceral hypersensitivity contribute to the development of functional dyspepsia. Although clinical and basic science studies of gastric hypersensitivity have focused primarily on responses to mechanical stimulation [e.g., distension; Tack et al. (2001), Ozaki et al. (2002)], the stomach is exposed to acid, bile, and a wide variety of ingested substances. Clinical data support a relationship between dyspeptic symptoms and the chemical composition of material in the proximal gastrointestinal tract (George et al., 1991; McColl and Fullarton, 1993; McColl, 1998; Schmulson and Mayer, 1998; Simren et al., 2003). Several studies have established the existence of chemosensitive extrinsic afferent nerves in the stomach and esophagus (Blackshaw, 1989; Sekizawa et al., 1999; Holzer, 2002;

Received July 16, 2004; revised Jan. 14, 2005; accepted Jan. 17, 2005

This study was supported by National Institutes of Health Grant Award NS35790. We thank Dr. Chris Benson for critical comments on this work and Mike Burcham for preparation of the figures.

Correspondence should be addressed to Dr. G. F. Gebhart, Department of Pharmacology, Bowen Science Building, Carver College of Medicine, The University of lowa, lowa City, IA 25542. E-mail: gf-gebhart@uiowa.edu. D0I:10.1523/JNEUROSCI.2894-04.2005

Copyright $\odot 2005$ Society for Neuroscience $\quad$ 0270-6474/05/252617-11\$15.00/0
Page et al., 2002), and we demonstrated recently that intragastric acid instillation at noninjurious concentrations acutely triggers visceromotor responses in rats (Lamb et al., 2003a,b). This aversive behavior was enhanced after inflammation of the stomach, thus providing experimental evidence for sensitization of visceral afferent pathways in chemonociception (Lamb et al., 2003b).

Changes in the properties of visceral sensory neurons contribute to the development of visceral hypersensitivity (Gebhart et al., 2004). Previous studies have established that protons trigger inward currents through amiloride-sensitive sodium channels in sensory neurons (Krishtal and Pidoplichko, 1981; Bevan and Yeats, 1991; Steen et al., 1992; Baumann et al., 1996; Waldmann et al., 1997), including visceral sensory neurons (Benson et al., 1999). Interestingly, the limited data available point to potential differences between the expression of these acid-sensitive currents in visceral compared with somatic neurons (Benson et al., 1999). Despite the acidic environment within the gastric lumen, the contribution of acid as an adequate noxious visceral stimulus, and the roles of spinal and vagal pathways in conveying nociceptive information to the CNS, the molecular sensor(s) encoding gastric acid chemonociception is not known. Accumulating evidence suggests that gastric vagal and spinal pathways contribute differentially to chemonociception (Schuligoi et al., 1998; Michl et al., 2001; Holzer, 2002, Lamb et al., 2003b), and we hypothesized that gastric dorsal root ganglion (DRG) and nodose gan- 
glion (NG) neurons express distinct acid-sensitive currents. To evaluate this hypothesis, we used the whole-cell patch-clamp technique to characterize acid-elicited currents in DRG and NG neurons that innervate the rat stomach. We also determined whether acid-elicited currents in gastric sensory neurons are altered after gastric ulceration, which produces hypersensitivity to gastric distension (Ozaki et al., 2002) and, thus, potentially contributes to peripheral sensitization of gastric sensory afferents. Portions of these data have been reported in abstract form (Sugiura et al., 2003).

\section{Materials and Methods}

Male Sprague Dawley rats (150-200 g; Harlan, Indianapolis, IN) were used for all experiments. The animals were fed a standard laboratory diet and maintained on a $12 \mathrm{~h}$ light/dark cycle (lights on 6:00 A.M. to 6:00 P.M.). All experimental procedures were approved by the Institutional Animal Care and Use Committee of The University of Iowa.

Labeling of gastric sensory neurons. To label gastric sensory neurons, rats were anesthetized with pentobarbital sodium (Nembutal, $45-50 \mathrm{mg}$ / kg, i.p.; Abbott Laboratories, Abbott Park, IL), and the stomach was exposed through a midline incision. A total of $2 \mu \mathrm{l}$ of the dicarbocyanine dye DiI [ $100 \mathrm{mg}$ in $2 \mathrm{ml}$ of dimethylsulfoxide (DMSO)] was injected into five sites within a $10 \mathrm{~mm}$ circular area on each of the dorsal and ventral surfaces of the antrum using a Hamilton microliter syringe with a 30 gauge needle. Thirty seconds after the injection, the needle was carefully removed, avoiding leakage of the dye into the peritoneal cavity. The abdomen was then closed, and the animals were allowed to recover. Visual inspection of the stomach 5-7 d after DiI injection did not reveal mucosal lesions or thickening of the gastric wall, suggesting that the label did not produce significant inflammation.

Induction of kissing ulcers. We adapted a previously described model of gastric ulceration produced by injection of acetic acid into a clamped area of the stomach (Lamb et al., 2003). Briefly, 7-14 d after DiI injection into the gastric wall, we performed a second laparotomy. The dorsal and ventral stomach was placed between a pair of circular clamps (inner diameter, $10 \mathrm{~mm}$ ) that encompassed the area marked by the previous DiI injection. In this model, the luminal surface of the stomach was accessed by injecting fluids between the pair of clamps. In the kissing ulcer (KU) group, $100 \mu \mathrm{l}$ of $60 \%$ acetic acid (HAc) was injected into the lumen between the clamps and completely withdrawn after $45 \mathrm{~s}$. Controls received an identical injection of sterile saline. The abdominal cavity was subsequently rinsed with sterile saline, the incision was closed, and animals were allowed to recover.

Cell preparation. Rats were anesthetized with pentobarbital sodium (as described above) and decapitated, and the NG and T9 and T10 DRG were quickly removed bilaterally under a dissection microscope, transferred into ice-cold culture media, and minced with a surgical blade. The ganglion tissue was incubated in DMEM (Invitrogen, San Diego, CA) containing collagenase (type $1 \mathrm{~A} ; 2 \mathrm{mg} / \mathrm{ml}$ ), trypsin (type III; $1 \mathrm{mg} / \mathrm{ml}$ ), deoxyribonuclease (type IV; $0.1 \mathrm{mg} / \mathrm{ml}$ ), and $3 \mathrm{~mm} \mathrm{CaCl}_{2}$ at $37^{\circ} \mathrm{C}$ for 50 $\mathrm{min}$. Chemical digestion was terminated by adding soybean trypsin inhibitor $(2 \mathrm{mg} / \mathrm{ml})$ and bovine serum albumin $(1 \mathrm{mg} / \mathrm{ml})$. The tissue fragments were then gently triturated with a sterile Pasteur pipette and centrifuged at $800 \mathrm{rpm}$ for $5 \mathrm{~min}$. NG and DRG neurons were resuspended in DMEM supplemented with 5\% rat serum and 2\% chick embryo extract, plated on poly-D-lysine-coated glass coverslips, and incubated for $2-24 \mathrm{~h}$ at $37^{\circ} \mathrm{C} 95 / 5 \%$ air $/ \mathrm{CO}_{2}$ atmosphere saturated with water vapor.

Whole-cell patch-clamp recordings. Patch pipettes were prepared using borosilicate glass (PG52151-4; World Precision Instruments, Sarasota, FL) with a tip resistance of $2-5 \mathrm{M} \Omega$ after fire polishing. They were filled with an internal solution containing the following (in mmol/L): $120 \mathrm{KCl}$, 5 EGTA, 10 HEPES, $2 \mathrm{MgCl}_{2}$, and $1 \mathrm{Na}_{2} \mathrm{ATP}$, adjusted to $\mathrm{pH} 7.4$ with $\mathrm{KOH}$. Extracellular solutions contained the following (in mmol/L): 128 $\mathrm{NaCl}, 5.4 \mathrm{KCl}, 1.8 \mathrm{CaCl}_{2}, 5 \mathrm{MgCl}_{2}, 5.55$ glucose, 10 HEPES, and 10 2-(N-morpholino)-ethanesulfonic acid (MES), pH adjusted with $\mathrm{NaOH}$. For solutions with $\mathrm{pH} 7.4, \mathrm{HEPES}$ concentration was increased to $20 \mathrm{mmol} / \mathrm{L}$; to adjust the $\mathrm{pH}$ below 4.5 , the MES concentration was raised to $20 \mathrm{mmol} / \mathrm{L}$. Solutions were applied through a three-barreled glass tubing manifold, $700 \mu \mathrm{m}$ in diameter, located $\sim 150 \mu \mathrm{m}$ from the cell. Rapid solution exchanges were achieved within $20 \mathrm{~ms}$ using a perfusion system (SF-77B; Warner Instruments, Hamden, CT). To avoid interference with current desensitization, we allowed 2 min between solution exchanges except for experiments to characterize recovery kinetics and current-clamp recordings. Gastric sensory neurons were identified by their red-orange color under Hoffman Contrast Optics $(400 \times)$ in fluorescent light with a rhodamine filter (excitation wavelength, $546 \mathrm{~nm}$; barrier filter, $580 \mathrm{~nm}$ ). Only DiI-labeled neurons were studied. We chose not to examine unlabeled DRG neurons because they represent a heterogeneous group of unidentified neurons, including those that innervate somatic structures, organs other than the stomach (e.g., esophagus, lower airways), and areas of the stomach not targeted by either the ulcer or retrograde tracer. Cell sizes were measured using a calibrated eyepiece. $\mathrm{Up}$ to $24 \mathrm{~h}$ after dissociation, the cells remained round and did not develop processes. The maximal diameter of the cell was determined by placing it under the grid at 400 -fold magnification. Whole-cell voltageclamp and current-clamp recordings were performed with an Axopatch 200B amplifier (Axon Instruments, Foster City, CA). Recordings were filtered at $5 \mathrm{kHz}$ and digitized at $1 \mathrm{kHz}$ using a Digidata $1320 \mathrm{~A}$ interface (Axon Instruments). For current-clamp experiments, only neurons with a stable resting membrane potential (RMP) of at least $-40 \mathrm{mV}$ were included in the study. Amiloride, capsaicin, and capsazepine (Sigma, St. Louis, MO) were dissolved in DMSO and applied at a final DMSO concentration of $<0.1 \% . \mathrm{ZnCl}_{2}$ and $N, N, N^{\prime}, N^{\prime}$-tetrakis-(2-pyridylmethyl)ethylenediamine (TPEN; Sigma) were dissolved in distilled water at a stock concentration of 100 and $20 \mathrm{~mm}$, respectively. All experiments were performed at room temperature $\left(21^{\circ} \mathrm{C}\right)$.

Histology. After removing the dorsal root and nodose ganglia, stomachs were removed, opened along the greater curvature, pinned flat, and fixed in $10 \%$ formalin in PBS. The HAc- or saline-treated area marked with DiI was removed, embedded in paraffin, cut into $4 \mu \mathrm{m}$ sections, and stained with hematoxylin and eosin. Mucosal integrity and inflammatory changes within the mucosa and deeper layers were assessed histologically.

Measurement of tissue $\mathrm{pH}$. Kissing ulcers were induced as described above. After $7 \mathrm{~d}$, animals were anesthetized with sodium pentobarbital, and the stomach was exposed through a midline incision. A miniaturized pH electrode (20 gauge, \#818; Diamond General Development, Ann Arbor, MI) was inserted into and advanced tangentially within the gastric wall. By coating the electrode with a colored marker (Evans blue), we determined that readings were obtained from the submucosa. Measurements were obtained in triplicate $2-5 \mathrm{~mm}$ distal of the fundus, a site that was $\sim 2 \mathrm{~cm}$ proximal of the ulcerated area. The electrode was then placed $2 \mathrm{~mm}$ proximally and distally of the ulcer (adjacent area) and into the ulcerated area itself. At the end of the experiments, the electrode was advanced into the gastric lumen, which was identified by a sudden drop in $\mathrm{pH}$.

Data analysis. Data are presented as mean \pm SEM. The software packages pClamp 9.0 (Axon Instruments) and Prism 4 (Graph Pad, San Diego, CA) were used for data acquisition and analysis. $\mathrm{pH}$ dose-response curves were fit to sigmoidal dose-response functions using the following equation: $Y=A /\left(1+\exp \left[-\left(X-\mathrm{pH}_{50}\right) / B\right]\right)$, where $X$ is the logarithm of concentration of proton and $Y$ is the response and starts at $O$ and ends at $A$ with a sigmoidal shape. The $\mathrm{pH}$ that gave half-maximal activation is presented as $\mathrm{pH}_{50}$. Kinetics of desensitization were fit to single exponential function using the following equation: $Y=K_{0}+K_{1} \times \exp (-t / \tau)$, where $Y$ is current amplitude at time $t, K_{0}$ is the amplitude of the sustained component, and $\tau$ is the time constant. $K_{0}$ and $K_{1}$ represent the contribution to current amplitude from the fast and slow components of the current, respectively.

Statistical significance was determined using Student's two-tailed unpaired $t$ test or two-way ANOVA. Differences were considered significant when $p<0.05$.

\section{Results}

Because visceral DRG cell diameters have been reported to be larger, on average, than somatic DRG cell diameters (Perry and Lawson, 1998; Su et al., 1999; Gold and Traub, 2004), we mea- 
sured acutely dissociated DRG and NG cell sizes (Fig. 1). Using a calibrated eyepiece, we measured the long axis of all neurons in the absence of fluorescent illumination (i.e., total) and then the long axis of DiI-labeled neurons under fluorescent illumination (i.e., DiI labeled). Of the total DRG neurons sampled, $64 \%$ had cell sizes $<30 \mu \mathrm{m}$; the remaining $36 \%$ of neurons were medium to large in size $(30-55 \mu \mathrm{m})$. The overwhelming majority of gastrointestinal afferent axons are unmyelinated or thinly myelinated (Sengupta and Gebhart, 1994), and sensory neurons with small-diameter cell bodies are believed to give rise to slowly conducting axons. However, almost all gastric DRG neurons labeled with DiI had medium to large cell sizes (Fig. $1 A$ ), consistent with previous data. The mean cell sizes for total and labeled DRG neurons were $27.6 \pm 0.7 \mu \mathrm{m}(n=100)$ and $40.5 \pm 0.5 \mu \mathrm{m}(n=$ $87 ; t=-14.14 ; p<0.001)$, respectively. Of the total NG neurons sampled, $60 \%$ had small-sized cell bodies; the remaining $40 \%$ of neurons had medium to large size cell bodies. These proportions were similar to the sizes of DRG neurons. Unlike labeled DRG cells, however, labeled NG neuron cell sizes were distributed across the range of cell sizes, although the mean cell sizes for total and labeled NG neurons significantly differed: $27.6 \pm 0.7 \mu \mathrm{m}$ $(n=100)$ and $31.3 \pm 0.5 \mu \mathrm{m}(n=132 ; t=-4.21 ; p<0.001)$, respectively.

The vanilloid (capsaicin) receptor, transient receptor potential vanilloid subtype 1 (TRPV1), has been proposed to identify sensory neurons as polymodal nociceptors, which are characteristically small in diameter, because of its activation by capsaicin, protons, and thermal (heat) stimuli (Caterina et al., 1999). Although gastric DRG neurons have medium- to large-diameter cell bodies, the majority of gastric DRG neurons (18 of 20) responded to $1 \mu \mathrm{M}$ capsaicin with an inward current (Fig. 1C). Fewer (59\%) gastric NG neurons (20 of 34) exhibited capsaicin sensitivity (independent of cell diameter) (Fig. 1C).

\section{Acid-elicited currents in gastric DRG neurons}

Rapid application of low-pH solutions to gastric DRG neurons triggered a transient inward current followed by a smaller sustained current that did not desensitize during the stimulus $(10 \mathrm{~s}$ duration) (Fig. 2A). The transient current could be further differentiated based on activation and desensitization kinetics into a fast type and slow type (Fig. 2 B). At pH 6.0, the fast-type transient component peaked at $218 \pm 56 \mathrm{~ms}$ and desensitized with a time constant of $210 \pm 50 \mathrm{~ms}(n=3)$ (Fig. $2 C, D)$. The slow-type transient component peaked at $789 \pm 51 \mathrm{~ms}$ and desensitized with a time constant of $2.79 \pm 0.31 \mathrm{~s}(n=13)$ (Fig. $2 B-D)$. All 50 gastric DRG neurons tested expressed transient acid-sensitive currents. Currents exhibiting a slow-type transient component predominated (43 of 50 neurons; $86 \%$ ); 7 of 50 DRG neurons (14\%) exhibited a rapidly activating and desensitizing fast-type acid-evoked current (Fig. $2 \mathrm{~A}$ ). In 20 of these neurons, we also examined the response to capsaicin (see above). Neurons with fast (2 of 2) and nearly all neurons with slow (16 of 18) protonevoked currents were capsaicin sensitive.

\section{Acid-elicited currents in gastric NG neurons}

In contrast to gastric DRG neurons, acid triggered transient inward currents in only 55\% of gastric NG neurons (23 of 42 neurons studied) (Fig. $2 A$ ). In 19 of these cells ( $45 \%$ of the total sample), this fast-type current was rapidly activated ( $\mathrm{pH} 6.0$ ) with a time to peak of $311 \pm 43 \mathrm{~ms}$; it desensitized with a time constant of $230 \pm 50 \mathrm{~ms}(n=10)$ (Fig. $2 B-D)$. A slow-type transient component was seen in only 4 of 42 neurons ( $10 \%$ of the sample) (Fig. 2A). It peaked at $968 \pm 20 \mathrm{~ms}$ and decayed with a time constant of $2.63 \pm 0.12 \mathrm{~s}(\mathrm{pH} 3.9 ; n=3)$ (Fig. $2 C, D)$. Nineteen of the 42 NG neurons studied ( $45 \%$ of the sample) exhibited only a sustained current during the application of acid (sustained type) (Fig. 2A). In 34 of these neurons, we also examined responses to capsaicin (see above). Capsaicin triggered currents in 5 of 13 neurons with fast acid-evoked currents, 15 of 18 neurons with sustained acid-evoked currents, but none of the three neurons with slow acid-evoked currents.

\section{Pharmacological properties of acid-sensitive currents}

To examine the contribution of acid-sensing ion channels (ASICs) to acid-elicited currents, we applied amiloride, a known blocker of the degenerin/ENaC (epithelial sodium channel) family (McCleskey and Gold, 1999). As shown by the examples illustrated in Figure 3, $A$ and $B$, amiloride significantly attenuated the transient component of the acid-sensitive current. In gastric DRG neurons, $200 \mu \mathrm{M}$ amiloride significantly decreased the peak transient current to a mean $51 \pm 6 \%$ of $\operatorname{control}(n=13 ; t=7.79$; $p<0.01)$. This effect did not differ when currents were elicited with solutions at pH 3.9 or pH 5.0 (Fig. 3 A, left and middle). Similarly, amiloride significantly attenuated inward currents triggered by low $\mathrm{pH}$ in fast-type NG neurons to a mean $33 \pm 3 \%$ of control (Fig. 3B, left) $(n=19 ; t=21.02 ; p<0.001)$.

In contrast to the effects on the transient current, amiloride did not affect the sustained current in slow-type DRG neurons ( $n=13 ; 93 \pm 6 \%$ of control) (Fig. $3 \mathrm{~A}$, left and middle) independent of the proton concentration used to trigger the current. In fast-type NG neurons, however, amiloride significantly attenuated the current to $63 \pm 5 \%$ of control at pH $3.9(n=14 ; t=6.62$; $p<0.001$ ) (Fig. 3B, middle); amiloride did not affect the sustained current in NG neurons at pH 5.0 (Fig. 3B, left) or in NG neurons that exhibited only a sustained acid-elicited current (Fig. $3 C$, left).

To investigate the subunit composition of ASIC channels in gastric sensory neurons, we examined the effects of several ASIC modulators. In this series of experiments, we activated ASICmediated currents submaximally by applying protons near the $\mathrm{pH}_{50}$ values for the principal currents in $\mathrm{NG}$ (fast, $\mathrm{pH}$ 5.2) and DRG (slow, $\mathrm{pH}$ 6.8) gastric neurons (see below for $\mathrm{pH}_{50}$ determinations). Coapplication of $\mathrm{Zn}^{2+}(300 \mu \mathrm{M})$, a coactivator of ASIC2a-containing channels (Baron et al., 2001), reversibly increased (Fig. $4 A$ ) the proton-activated current in 10 of 26 DRG neurons to $210 \pm 40 \%$ of control $(p<0.05)$. Zinc inhibited acid-sensitive currents to $46 \pm 6 \%$ in 9 of 26 neurons $(p<0.05)$ (Fig. $4 B$ ). Despite this apparent difference, neurons in both groups exhibited slowly activating currents in response to protons with similar time constants of desensitization $(2.36 \pm 0.38 \mathrm{vs}$ $1.71 \pm 0.33 \mathrm{~s}$ for potentiated or inhibited currents, respectively). In the remaining seven cells, zinc did not affect peak amplitude or kinetics of proton-activated currents. In contrast to its effects on the slowly desensitizing current, $\mathrm{Zn}^{2+}$ (Fig. 4C,D) had no effects on the fast desensitizing and sustained currents in seven gastric NG neurons tested (108 \pm 10 and $112 \pm 7 \%$ of control for fast desensitizing and sustained component, respectively; NS). Similarly, the $\mathrm{Zn}^{2+}$ chelator TPEN, which potentiates ASIC1acontaining channels (Chu et al., 2004), had discordant effects on slowly desensitizing currents in DRG neurons, increasing peak currents in 9 of 26 neurons to $330 \pm 80 \%$ of control $(p<0.05)$ while decreasing currents in six neurons to $53 \pm 16 \%$ of control $(p<0.05)$. TPEN did not affect currents in the remaining 11 neurons. TPEN did not alter the rapidly desensitizing and sustained currents in seven gastric nodose neurons tested $(97 \pm 10$ 

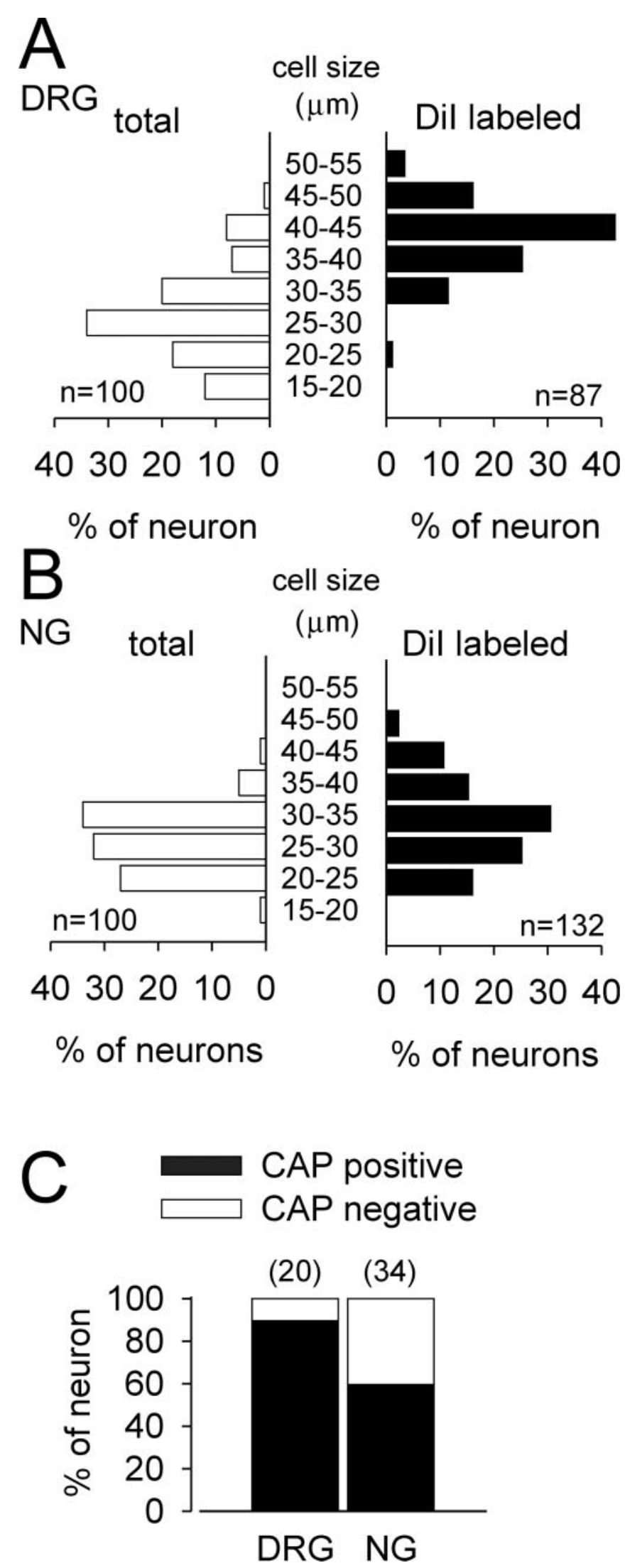

Figure 1. Cell sizes of DRG $(\boldsymbol{A})$ and NG $(\boldsymbol{B})$ neurons and capsaicin (CAP) sensitivity of gastric DRG and NG neurons ( $(\boldsymbol{C}$. In $\boldsymbol{A}$ and $\boldsymbol{B}$, total neurons represent the length of the long axis of all neurons in the absence of fluorescent illumination, which is widely distributed in cell size, and are in contrast to gastric DRG and NG neurons labeled with Dil. Sensitivity to $1 \mu$ m capsaicin is represented as a percentage of the numbers of gastric DRG and NG neurons tested (shown above bars). and $103 \pm 6 \%$ of control for fast desensitizing and sustained component, respectively; NS).

We also examined the relative contribution of the capsaicin receptor (TRPV1), another channel gated by protons, to the acidelicited currents using the channel blocker capsazepine. At a concentration of $10 \mu \mathrm{M}$, capsazepine significantly attenuated the sustained acid-elicited current by $46 \pm 13 \%$ (Fig. $3 C$, right) $(n=6$; $t=3.59 ; p<0.05$ ) in NG neurons that exhibited only a sustained current, all of which also showed capsaicin sensitivity. The inhibitory effect of capsazepine did not fully reverse after 2 min of washout. Interestingly, $10 \mu \mathrm{M}$ capsazepine did not significantly alter the sustained component in DRG neurons ( $95 \pm 1 \%$; $n=4$ ), nor did capsazepine affect the transient components of the acidevoked current in NG or DRG neurons (Fig. $3 A, B$, right traces).

Considering the differences noted in acid-elicited currents between DRG and NG neurons, we estimated whether cell size or sensitivity to capsaicin correlated with and could be potential predictors for response to acid. A total of 90\% (18 of 20) of DRG neurons tested responded to capsaicin $(1 \mu \mathrm{M})$, and cell diameter was the same for neurons with slow- or fast-type acid-elicited transient currents. Accordingly, capsaicin sensitivity is not a good discriminator for acid-sensitive gastric DRG neurons. Of the thirteen NG neurons with fast-type acid-evoked transient currents, only 5 of $13(38 \%)$ also responded to $1 \mu \mathrm{M}$ capsaicin. In contrast, 15 of $18 \mathrm{NG}$ neurons (83\%) exhibiting only sustainedtype acid-sensitive currents responded to capsaicin. No gastric NG neurons with a slow-type transient current responded to capsaicin $(n=3)$.

\section{$\mathrm{pH}$ dependence of acid-elicited currents in gastric sensory neurons}

To further characterize the properties of acid-sensitive currents in gastric sensory neurons and characterize the subtype of ASICs defined by distinct $\mathrm{pH}_{50}$, we examined the $\mathrm{pH}$ dependence of these currents using solutions with a $\mathrm{pH}$ between 7.2 and 3.9. We allowed 2 min between each $10 \mathrm{~s}$ application to assure full current recovery. As shown in Figure 5, $A$ and $B$, the transient component of the slowly desensitizing current in DRG neurons is activated at approximately pH 7.0 with half-activation at $\mathrm{pH} 6.7 \pm 0.04(n=$ 17). The transient component of the fast-type current required a $\mathrm{pH}$ of $6.4 \pm 0.1$ for half-activation $(n=4 ; t=2.83 ; p<0.05$ compared with the slow-type current).

The kinetic properties of the transient acid-elicited currents in NG neurons did not differ from those in DRG neurons, but significantly higher proton concentrations were required for activation of acid-elicited currents in NG cells. The $\mathrm{pH}$ of halfactivation was $5.1 \pm 0.2(n=18)$ for the fast-type and $4.3 \pm 0.2$ for the slow-type $(n=4 ; t=2.43 ; p<0.05)$ transient component of the current (Fig. 5C,D). In NG cells exhibiting only sustainedtype acid-sensitive currents, the current was half-activated at a $\mathrm{pH}$ level of $5.3 \pm 0.1(n=18)$ (Fig. $5 C$, right, $D)$.

\section{Recovery from desensitization}

To more fully characterize the subtype of ASIC current, we examined recovery from desensitization of acid-elicited transient currents in the principal current types found in DRG neurons (slowly desensitizing or slow-type, representing $86 \%$ of the sample) and NG neurons (rapidly desensitizing or fast-type, representing $83 \%$ of neurons that exhibited transient currents). We applied an acidic solution (approximately $\mathrm{pH}_{50}$ ) for $10 \mathrm{~s}$, followed by a switch to $\mathrm{pH}$ 7.4. Acid-sensitive currents were triggered again between 0.25 and $90 \mathrm{~s}$ after cessation of the initial application. The normalized peak currents elicited by the second 


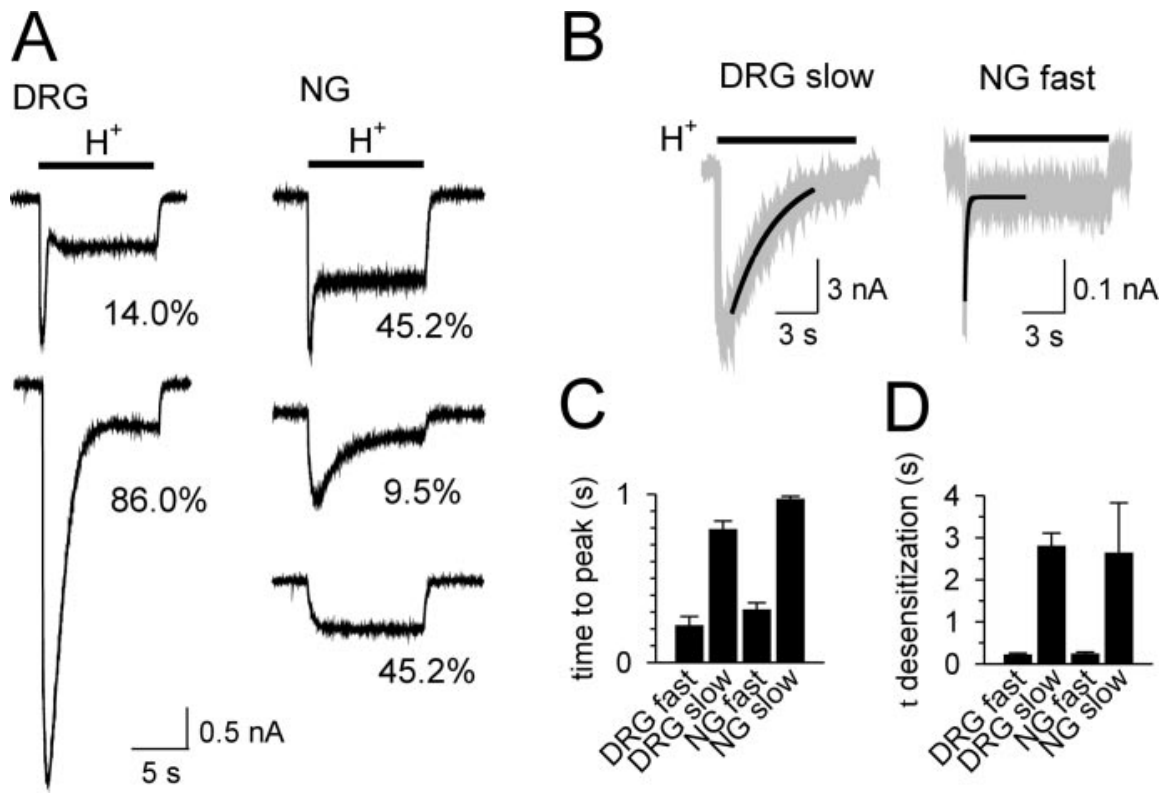

Figure 2. Representative acid-elicited currents in gastric DRG and NG neurons ( $\boldsymbol{A}$ ); proportions of current types (see Results) in DRG and NG neurons studied are indicated. The bar indicates application of low-pH solution $\left(\mathrm{H}^{+} ; \mathrm{pH} 5.0\right)$. $\boldsymbol{B}$, Representative current tracings triggered by $\mathrm{pH} 6.0$ demonstrate the overlap between the single exponential fit (thick line) and the original recording (gray line) for the slow (left) and fast (right) components of the transient current. The data for time to peak activation (C) and time constant of desensitization $(\boldsymbol{D})$ of acid-elicited currents are summarized for DRG (fast-type, $n=3$; slow-type, $n=13$; both at pH 6.0) and NG (fast-type, $n=10, \mathrm{pH} 6.0$; slow-type, $n=3, \mathrm{pH} 4.6$ ) neurons.

acid stimulation were plotted as a function of the interstimulus interval. As shown in Figure 5, $E$ and $F$, the rapidly desensitizing component of the current in NG neurons recovered within $<1 \mathrm{~s}$, whereas the slowly inactivating component of the current required $90 \mathrm{~s}$ for full recovery from desensitization. The time courses of recovery followed a single exponential function with a time constant of $7.73 \pm 0.11 \mathrm{~s}(n=3)$ in slow-type DRG neurons and $283.3 \pm 109.9 \mathrm{~ms}$ in fast-type NG neurons $(n=6)$ (Fig. $5 F)$. Because rapidly and slowly desensitizing currents were only rarely seen in DRG and NG neurons, respectively, we were not able to systematically analyze differences in the recovery kinetics between these neurons.

\section{Extracellular acidification can trigger firing in gastric afferent neurons}

To examine whether extracellular acidification depolarizes the membrane potential sufficiently to generate action potentials, we determined in current-clamp recordings the threshold $\mathrm{pH}$ for generation of an action potential by applying low-pH solutions ( $\mathrm{pH} 7.2,7.0,6.8,6.6,6.3,6.0$, and 5.5) (Fig. 6A). The majority of gastric DRG neurons responded to acid at $\mathrm{pH} 7.0$ or 6.8 , but the threshold $\mathrm{pH}$ for firing was lower in gastric NG neurons. These data are consistent with $\mathrm{pH}$ sensitivity determined in voltageclamp recordings in gastric sensory neurons (Fig. 5) (note predominant slow-type in DRG neurons and fast-type and sustained in NG neurons). In inflamed tissue such as the base of an ulcer, ambient $\mathrm{pH}$ is constantly reduced. Because elevated proton concentrations may alter membrane excitability, we first examined the $\mathrm{pH}$ effect on the rheobase by increasing depolarizing current injections ( $5 \mathrm{~ms}$ duration) until an action potential was generated (Fig. $6 B$ ). The thresholds determined in this way were $-30.6 \pm$ $1.8 \mathrm{mV}(n=18),-43.3 \pm 3.6 \mathrm{mV},(n=7)$, and $-33.2 \pm 2.5 \mathrm{mV}$ $(n=7)$ for slow-type DRG neurons, fast-type NG neurons, and sustained-type $\mathrm{NG}$ neurons, respectively, $\mathrm{pH}$ 7.4. Acidification of the extracellular solution ( $1 \mathrm{~min}$; $\mathrm{pH}$ 6.6) significantly raised the threshold potential for neurons expressing transient acidevoked currents, whereas the threshold potential for sustained-type NG neurons was not affected by low-pH solution (Fig. 6C) $(\mathrm{pH} 6.6 ;-31.5 \pm 2.7 \mathrm{mV} ; n=7)$. Neuron classification was confirmed by switching from current-clamp to voltageclamp mode. The membrane potential did not exceed threshold constantly during prolonged application of $\mathrm{pH} 6.6$ solution but transcended it during exposure to $\mathrm{pH}$ 5.5 solution in slow-type DRG and sustained-type NG neurons (Fig. 6D). Consistent with $\mathrm{pH}$ sensitivity of the acidevoked current in fast-type NG neurons (Fig. $5 C, D$ ), a greater concentration of protons was required for continuous depolarization of the cell membrane over the threshold (Fig. 6E). Even after prolonged exposure to acidic solution ( $\mathrm{pH}$ 6.6), an additional decrease to $\mathrm{pH} 5.5$ was able to trigger action potentials in gastric sensory neurons. The number of action potentials evoked by acidic solution ( $\mathrm{pH} 5.5)$ at $\mathrm{pH}$ 6.6 was significantly higher in sustainedtype NG neurons $(n=6 ; 9.8 \pm 1.8)$ than slow-type DRG neurons $(n=7 ; 3.0 \pm 1.2$; $t=-3.21 ; p<0.01)$ and fast-type NG neurons $(n=6 ; 2.7 \pm 1.9$; $t=-2.75 ; p<0.05$ ) (Fig. $6 F$ ). Consistent with the difference in the number of action potentials, spiking lasted longer in sustained-type NG neurons $(n=6 ; 257.7 \pm 52.7)$ than slow-type DRG neurons $(n=7 ; 75.0 \pm 34.4 ; t=-2.99 ; p<0.05)$ (Fig. $6 G$ ).

\section{Effects of experimental ulcers on gastric afferent neurons}

Consistent with previous reports (Lamb et al., 2003b), intraluminal application of $60 \%$ HAc produced ulcers in the gastric mucosa. Microscopically, the mucosa was completely disrupted beyond the level of the muscularis mucosae with granulation tissue covering the area and an inflammatory infiltrate extending into the submucosa and muscularis (Fig. 7A, left). In contrast, control animals treated with saline showed no mucosal injury or inflammatory infiltrate (Fig. 7A, right).

Proton concentration was measured within the gastric wall in three animals with ulcers, using a pH-sensitive microelectrode. At a site distant from the ulcer, the $\mathrm{pH}$ within the gastric wall was $7.24 \pm 0.06$, which did not differ from controls $(7.27 \pm 0.02 ; n=$ $3)$. The proton concentration was significantly greater in areas adjacent to the ulcer $(\mathrm{pH}, 6.79 \pm 0.07)$ and within the ulcer base $(\mathrm{pH}, 6.6 \pm 0.02 ; t=4.52 ; p<0.01$ compared with distant site). Gastric luminal $\mathrm{pH}$ was $4.39 \pm 0.25$ and $3.8 \pm 0.19$ in control and KU animals $(t=1.98 ; p>0.05)$, respectively.

\section{Gastric DRG neurons}

Figure $7 B$ summarizes data of the slow-type acid evoked current from 40 of 54 DRG neurons derived from rats $7 \mathrm{~d}$ after production of ulcers, a time at which hypersensitivity to balloon distension of the stomach and to intraluminal instillation of $\mathrm{HCl}$ is prominent (Lamb et al., 2003b). Similar to neurons obtained from nonulcer, control rats, all gastric DRG neurons from rats with ulcers expressed transient acid-sensitive currents. The most common response to acid was a slowly desensitizing transient 


\section{A DRG slow}
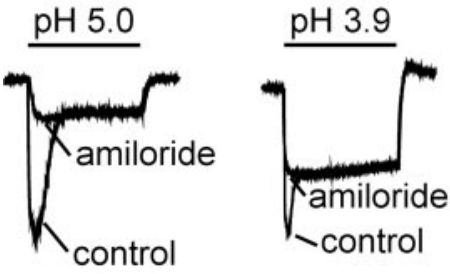

\section{B NG fast}
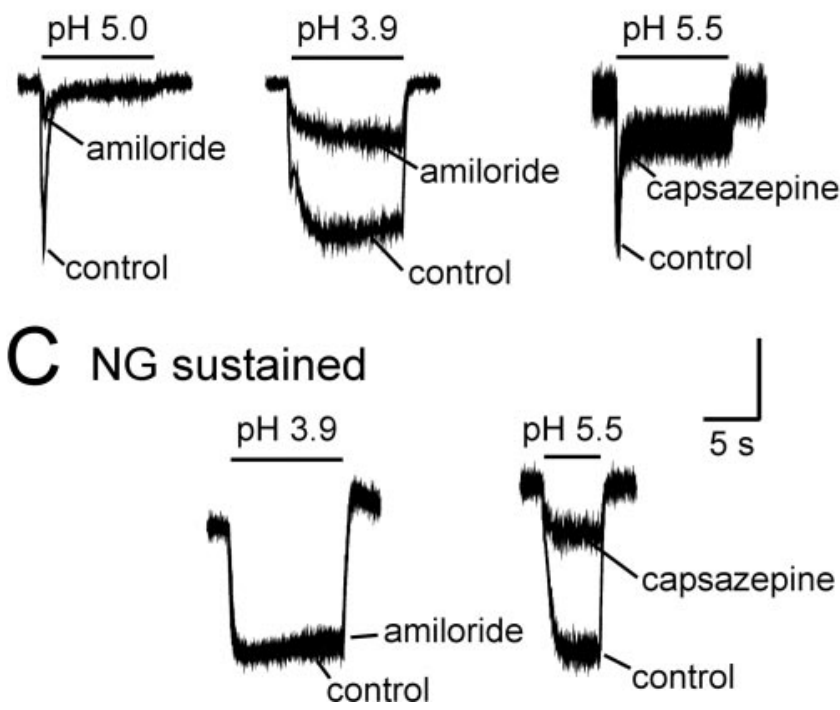

Figure 3. Representative effects of amiloride and capsazepine on acid-elicited currents in gastric sensory neurons. Amiloride ( $200 \mu \mathrm{M}$ ) attenuated the acid-elicited transient component of the currents in DRG $(\boldsymbol{A})$ and NG $(\boldsymbol{B})$ neurons but not the sustained component of the current in gastric DRG neurons. $\boldsymbol{B}$, Amiloride did not affect the sustained component of the current in gastric NG neurons at $\mathrm{pH} 5.0$ but was effective when the current was elicited by low pH. $\boldsymbol{A}, \boldsymbol{B}$, Capsazepine $(10 \mu \mathrm{M})$ did not affect either the transient or sustained components of the acidelicited current in gastric DRG or NG neurons. C, Amiloride was without effect in NG neurons exhibiting only a sustained acid-elicited current, but capsazepine significantly attenuated the current. Vertical calibration: $A$, left, $2.0 \mathrm{nA}$; middle, $2.5 \mathrm{nA}$; right, $3.2 \mathrm{nA}$; $\boldsymbol{B}$, left, $1.0 \mathrm{nA}$; middle, $1.0 \mathrm{nA}$; right, $0.14 \mathrm{nA}$; $C$, left, $0.64 \mathrm{nA}$; right, $0.64 \mathrm{nA}$. Horizontal calibration, $5 \mathrm{~s}$ for all traces.

current (75\% of the sample), as in controls. Gastric ulcers affected the slow-desensitizing component of the transient current (Fig. $7 B$, left $)(F=11.87 ; p<0.001)$. The slowly desensitizing component of the transient current activated at a significantly lower proton concentration $(\mathrm{pH}$ of half-activation, $6.9 \pm 0.04$; $n=18 ; t=-2.16 ; p<0.05$, compared with saline controls) (Fig. $7 B$, left). This represents a significant shift of the $\mathrm{pH}$ dependence of activation to lower proton concentrations. Regarding the sustained component of the current in slow-type DRG neurons, gastric ulceration significantly affected $\mathrm{pH}$ sensitivity $(F=20.24$; $p<0.001$ ) (Fig. $7 B$, right); the current density was significantly greater at higher proton concentrations. We also observed significant changes in the kinetic properties of the transient component of the acid-sensitive current in slow-type DRG neurons after induction of gastric ulcers. The time to peak was $690 \pm 63 \mathrm{~ms}$ ( $n=15 ; t=1.20 ; p>0.05$ compared with saline controls), although the slow component of the current desensitized more rapidly with a time constant of $1966 \pm 124 \mathrm{~ms}(n=15 ; t=2.58$; $p<0.05$ compared with saline controls). However, there was no effect of ulceration on the amplitude of the capsaicin-evoked

\section{A DRG}
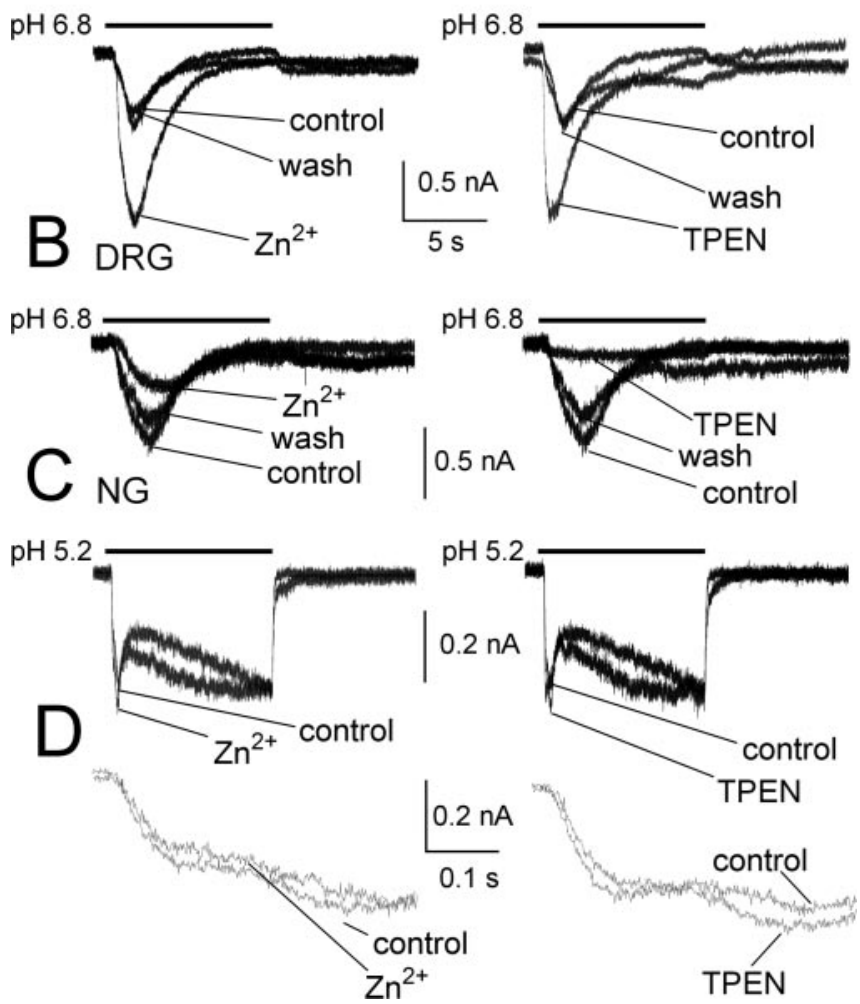

Figure 4. Modulation of proton-activated currents by $\mathrm{Zn}^{2+}$ and TPEN in gastric sensory neurons. $A, Z^{2+}$ and TPEN potentiated the transient current evoked by protons in the same gastric DRG neuron (left and right, respectively) (see Results for details). B, Conversely, $\mathrm{Zn}^{2+}$ and TPEN inhibited the current in another neuron. The effects of $\mathrm{Zn}^{2+}$ or TPEN fully recovered after washout. $C$, In contrast, neither $\mathrm{Zn}^{2+}$ nor TPEN had any effects on gastric NG neurons. Note that all traces in $\boldsymbol{C}$ were taken from the same cell. $\boldsymbol{D}$, The same traces as shown in $\boldsymbol{C}$, but in expanded time scale to illustrate that the fast-desensitizing component was not affected by $\mathrm{Zn}^{2+}$ or TPEN.

current in slow-type gastric DRG neurons tested, all 19 of which responded to $1 \mu \mathrm{M}$ capsaicin (Fig. $7 D$, top).

\section{Gastric NG neurons}

Similar to NG neurons taken from sham (control) rats, acid triggered transient inward currents in most (32), but not all, of the 47 NG neurons examined. The remaining neurons expressed only sustained-type currents. The peak current density and $\mathrm{pH}$ sensitivity of acid-sensitive currents did not differ between fast-type NG neurons from controls and rats with ulcers (Fig. 7C, top; $D$, middle). Gastric inflammation also did not affect the $\mathrm{pH}$ sensitivity in sustained-type NG neurons (Fig. $7 C$, bottom). Ulceration, however, did affect the kinetic properties of the rapidly desensitizing transient current, which activated significantly faster in NG neurons from rats with ulcers (time to peak, $191 \pm 9$ $\mathrm{ms} ; n=16 ; t=2.97 ; p<0.01$ compared with saline controls); the desensitization time constant was not altered (204 $\pm 17 \mathrm{~ms})$. After induction of ulcers, the amplitude of the capsaicin-evoked current tended to be greater in gastric NG neurons but was not significantly different from control (Fig. $7 D$, bottom).

\section{Discussion}

Because gastric acid is important in the pathogenesis of dyspeptic symptoms, we examined acid-sensitive ion currents in gastric sensory neurons. All of the gastric sensory neurons studied re- 

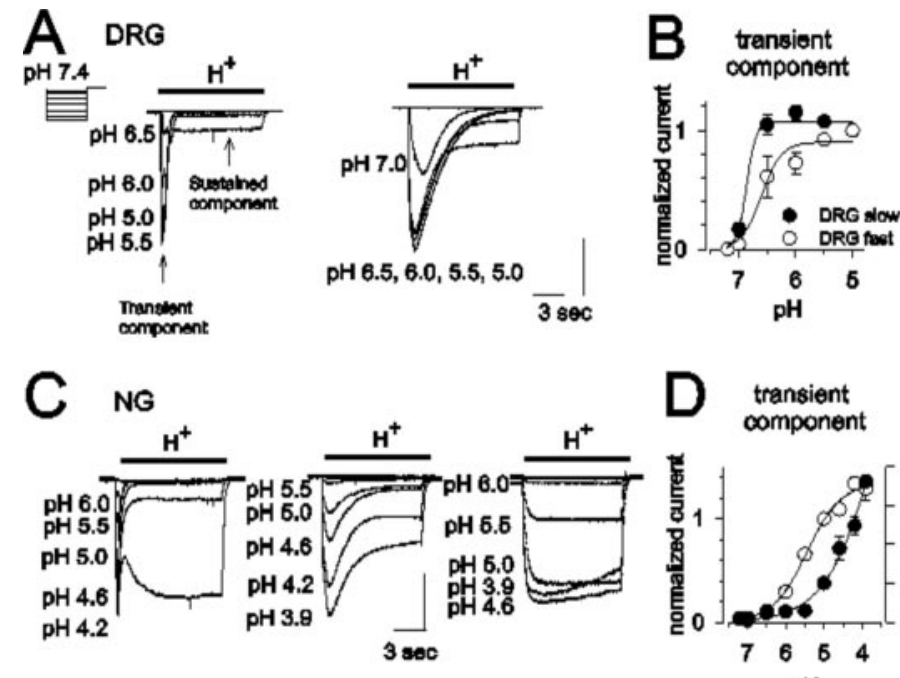

E
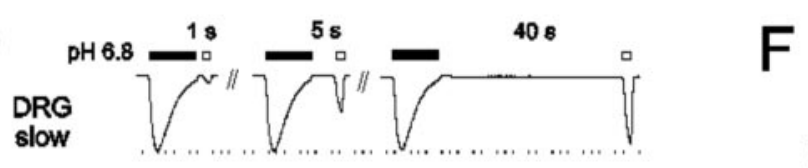

Figure 5. $\mathrm{pH}$ concentration-response relationships in gastric DRG and NG neurons. Representative records of acid-elicited currents from a holding pH of 7.4 in gastric DRG $(\boldsymbol{A})$ and NG $(\boldsymbol{C})$ neurons. $\boldsymbol{B}$ and $\boldsymbol{D}$ summarize the pH sensitivity of transient and sustained currents in gastric DRG and NG neurons, respectively. Currents were normalized to those elicited by pH 5.0. Unfilled circles, Fast-type (DRG, $n=4 ; \mathrm{NG}, n=18$ ); filled circles, slow-type (DRG, $n=24 ; \mathrm{NG}, n=4)$; triangles, sustained-type $(n=18)$. Vertical calibration: $\boldsymbol{A}$, left, $0.8 \mathrm{nA}$; right, $1.8 \mathrm{nA}$; $\boldsymbol{C}$, left, $0.6 \mathrm{nA}$; middle, $1.0 \mathrm{nA}$; right, $1.0 \mathrm{nA}$. Horizontal calibration, 3 s for all traces in $\boldsymbol{A}$ and $\boldsymbol{C}$. $\boldsymbol{E}$, Recovery kinetics of typical transient currents in gastric DRG (top; slow-type) and NG (bottom; fast-type) neurons. An initial 10 s exposure to acid for complete desensitization (filled bar; pH 6.8 in DRG neurons and pH 5.5 in NG neurons) was followed by a second, $2 \mathrm{~s}$ test stimulus at the same $\mathrm{pH}$ at varying interstimulus intervals (unfilled bars). $\boldsymbol{F}$, Time courses of recovery from desensitization. The peak amplitude of the current elicited by the test stimulus was normalized to that of the initial desensitizing stimulus. The time constant was $7.73 \pm 0.11 \mathrm{~s}$ in slow-type DRG neurons (unfilled circles; $n=3$ ) and $283.3 \pm 109.9 \mathrm{~ms}$ in fast-type NG neurons (filled circles; $n=6$ ).

sponded to transient decreases in $\mathrm{pH}$, but the pattern, sensitivity to protons, and pharmacological characteristics of acid-sensitive currents differed significantly between vagal (NG) and spinal (DRG) neurons. Moreover, experimentally induced gastric ulcers significantly altered the properties of spinal and, to a lesser degree, vagal sensory neurons.

The present findings in gastric DRG neurons are consistent with those reported by Benson et al. (1999). They reported that 93\% of rat cardiac DRG neurons responded to protons, whereas only approximately half of the unlabeled, presumably somatic DRG neurons in the sample responded to protons. Because ischemia is the most common cause of cardiac pain and is associated with a decrease in tissue $\mathrm{pH}$ (Pan et al., 1999), the difference noted between somatic and cardiac neurons led to speculation about the role of acid-sensitive currents in cardiac nociceptors (Benson and Sutherland, 2001). We cannot comment on the differential expression of acid-sensitive ion currents in somatic and visceral sensory neurons, but it is clear that there are differences in these currents within the visceral sensory neuron population and thus likely between visceral and somatic neurons. In contrast with the results of Benson et al. (1999), who noted acid-elicited currents in $74 \%$ of cardiac NG neurons, all gastric NG neurons
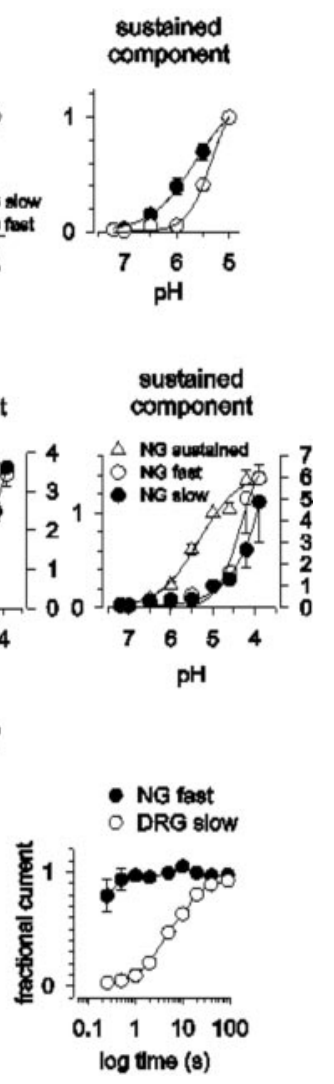

studied here responded to acid. Interestingly, gastric NG neurons generated action potentials in response to depolarizing current injections or additional increases in proton concentration even after prolonged exposure to $\mathrm{pH}$ 6.6, which may reflect the importance of gastric vagal afferents in the regulation of acid secretion and in chemonociception (Ramos et al., 1992; Holzer, 2002; Schicho et al., 2004).

\section{ASICs and gastric sensory neurons}

Because amiloride, a known blocker of members of the $\mathrm{ENaC} /$ degenerin family, inhibited the transient acid-sensitive current, the transient component of acidsensitive ion currents in gastric DRG and NG neurons is mediated by ASICs. The proton sensitivity and kinetic properties of the rapidly desensitizing, transient acidsensitive current in gastric DRG neurons are similar to those seen in rat cardiac sensory neurons and in heterologously expressed ASIC3 channels (Table 1) (Sutherland et al., 2001; Benson et al., 2002). Similarly, the kinetic properties of the rapidly desensitizing, transient acid-sensitive current in NG neurons resembles currents mediated by ASIC3, although the $\mathrm{pH}$ sensitivity of gastric NG neurons in the present study is significantly lower than reported for the murine clone of the ASIC3 channel alone or coexpressed with other murine ASIC subunits (Table 1) (Benson et al., 2002).

The properties of the slowly inactivating component of the transient current, the most commonly seen pattern in gastric DRG neurons ( $86 \%$ of neurons studied), are consistent with those described for ASIC1 $\alpha$ (Benson et al., 2002). We found no differences in the activation and desensitization kinetics between the slowly decaying acid-sensitive currents recorded in gastric DRG and NG neurons. However, the proton sensitivity of the slowly desensitizing component of the current in NG neurons was significantly lower compared with DRG neurons in the present study and with previously published reports on properties of ASICs in mouse and rat sensory neurons, except for ASIC2a/ASIC2b heteromultimers expressed in Xenopus oocytes (Table 1) (Chen et al., 1998; Benson et al., 2002; Ugawa et al., 2003). Interestingly, expression of rat ASIC3 in Xenopus oocytes (Babinski et al., 2000; Benson et al., 2002) demonstrated a lowerproton sensitivity compared with mammalian expression systems (Benson et al., 2002), suggesting that other associated subunits may be involved in modifying properties of acid-sensitive currents. To further evaluate the subunit composition of native ASIC channels expressed in gastric sensory neurons, we examined effects of two known modulators: $\mathrm{Zn}^{2+}$ and TPEN, a positive and negative modulator of ASIC2a and ASICla subunits, respectively (Baron et al., 2001; Chu et al., 2004). Although $\mathrm{Zn}^{2+}$ had no effect in some cells, consistent with previous findings reported for hippocampal and cortical neurons (Baron et al., 2002; Chu et al., 2004), $\mathrm{Zn}^{2+}$ significantly increased the proton- 
evoked current in $\sim 40 \%$ of gastric DRG neurons, suggesting that ASIC2a is expressed in rat gastric DRG neurons. In addition, $\mathrm{Zn}^{2+}$ also inhibited the protonevoked current in $\sim 45 \%$ of gastric DRG neurons, suggesting that other ASIC subunits, possibly ASIC1a, may also be present in these neurons. Despite the highproton sensitivity and kinetic properties that resemble ASIC1a subunits expressed in heterologous systems (Benson et al., 2002; Hesselager et al., 2004), TPEN increased the acid-elicited current only in $\sim 40 \%$ of gastric DRG neurons. These results do not yield a clear interpretation, and additional studies will be required to identify the subunits and associated proteins potentially mediating transient acidsensitive currents in NG neurons.

\section{TRPV1 and gastric sensory neurons}

Protons also modulate the gating of the heat-sensitive ion channel TRPV1, suggesting that this channel may be involved in the transduction of chemical stimuli in addition to capsaicin (Baumann and Martenson, 2000; Jordt et al., 2000; Tominaga et al., 2001). In contrast with previous reports in cardiac or colon DRG neurons (Del Mar et al., 1996; Benson et al., 1999; Su et al., 1999), 90\% of gastric DRG neurons responded to capsaicin. Although a higher fraction of small-diameter DRG neurons expresses TRPV1 channels (Del Mar et al., 1996; Vyklicky et al., 1998; Michael and Priestley, 1999), the mean diameter of labeled gastric DRG neurons was significantly larger than that of unlabeled DRG neurons (Fig. 1), arguing against a confounding effect of cell size.

Consistent with the expression of TRPV1 in rat NG neurons (Ichikawa and Sugimoto, 2003), $\sim 60 \%$ of the gastric NG neurons we studied responded to $1 \mu \mathrm{M}$ capsaicin, and most exhibited only a sustained proton-elicited current. Moreover, the TRPV1 receptor blocker capsazepine, but not amiloride, significantly attenuated this sustained-type current in NG neurons, although high concentrations of capsazepine may affect other ion channels (Bielefeldt, 2000). Considering the lack of inhibitory effects of capsazepine on acidsensitive currents in gastric DRG neurons, the present results suggest that protons directly activate TRPV1 in gastric NG but not DRG neurons. Similar results have been reported in trigeminal ganglion neurons (Liu and Simon, 2000). Protons did not effectively activate TRPV1 receptors expressed in Xenopus oocytes (Caterina et al., 1997), whereas they triggered slowly activating, sustained inward currents in human embryonic kidney 293 cells transfected with TRPV1 (Tominaga et al., 2001). These
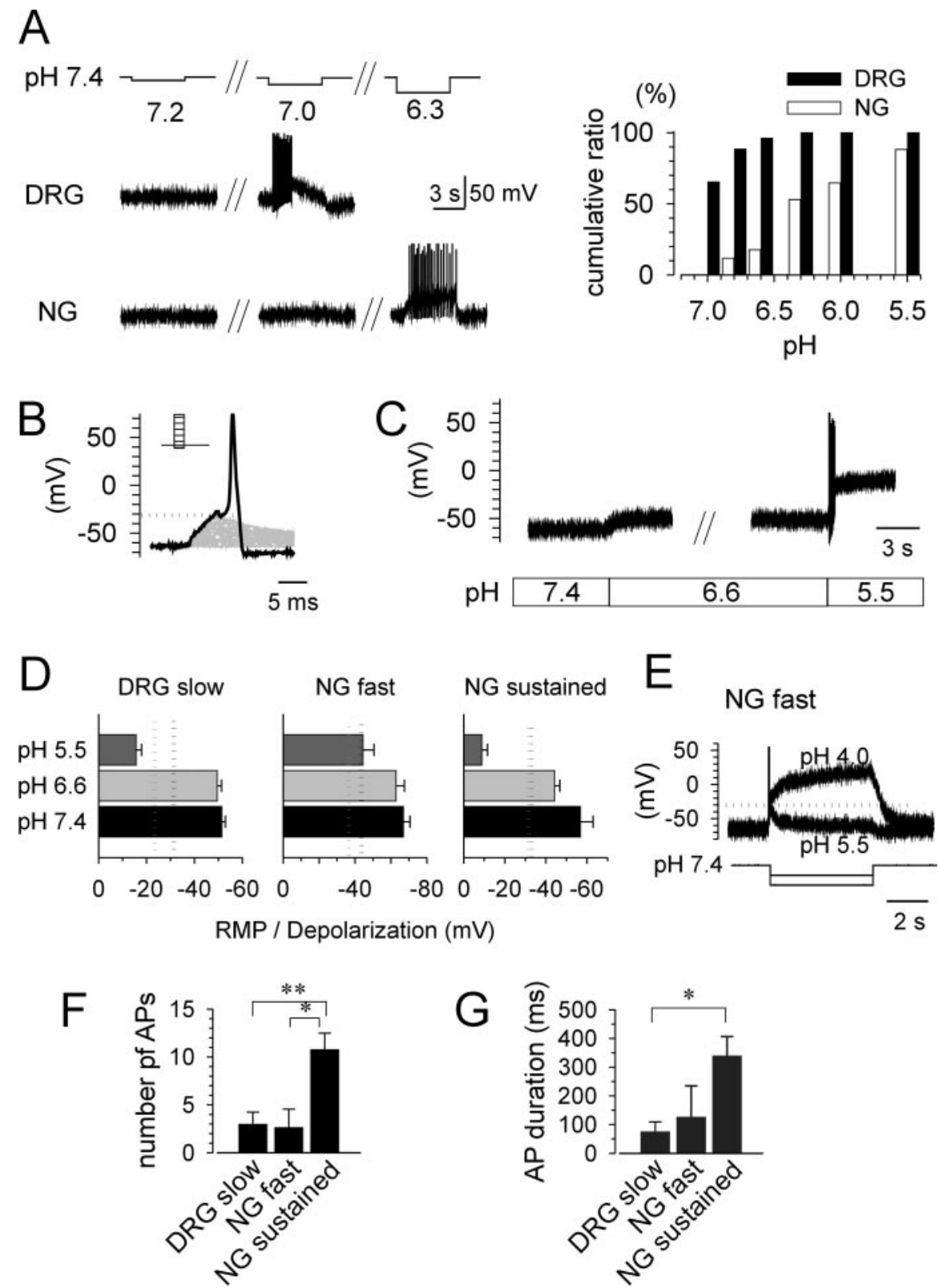

Figure 6. Extracellular acidification triggers action potentials in gastric DRG and NG neurons. $A$, Representative traces of membrane potential and action potentials in the presence of low-pH solutions ( $\mathrm{pH} 7.2,7.0,6.8,6.6,6.3,6.0$, and 5.5) applied for $5 \mathrm{~s}$. The right panel shows the cumulative ratio of responses to low pH in gastric DRG $(n=26)$ and NG $(n=17)$ neurons. $\boldsymbol{B}$, Representative trace to illustrate determination of the threshold for action potential generation by current injection (5 ms) in gastric sensory neurons. The injected current was increased stepwise until an action potential was evoked, illustrated by the dotted line. C, Representative traces of acid-evoked depolarization in gastric NG neurons. Membrane potential stabilized after prolonged application of low-pH solutions. $\boldsymbol{D}$, Summary data for comparison RMP and acid (pH 6.6, 5.5)-induced depolarization (during the stable phase) with threshold membrane potentials for generating action potential determined by current injection. The classification of neurons (fast, slow, and sustained types) was confirmed by switching to voltage-clamp mode after measurements. Dotted lines indicate the mean threshold for generation of action potentials by current injection at pH 7.4 (black) (DRG slow, $n=18,-30.6 \pm 1.8 \mathrm{mV} ; \mathrm{NG}$ fast, $n=7,-43.3 \pm 3.6 \mathrm{mV}$; NG sustained, $n=7,-33.2 \pm 2.5 \mathrm{mV}$ ) and pH 6.6 (gray) (DRG slow, $n=18,-23.7 \pm 2.5 \mathrm{mV}$; NG fast, $n=7,-36.4 \pm 4.0 \mathrm{mV}$; NG sustained, $n=7,-31.5 \pm 2.7 \mathrm{mV}$ ). $\boldsymbol{E}$, NG fast-type neurons required a much higher concentration of protons to depolarize neurons above threshold for generation of action potentials. $\boldsymbol{F}, \boldsymbol{G}$, The number of action potentials $(\boldsymbol{F})$ and duration of action potential generation $(\boldsymbol{G})$ evoked by acidic solution (pH 5.5) at pH 6.6 was significantly larger in sustained-type NG neurons $(n=6)$ than in slow-type DRG neurons $(n=7)$ and fast-type NG neurons $(n=6)$. AP, Action potential. ${ }^{*} p<0.05 ;{ }^{* *} p<0.01$.

data suggest that posttranslational modulation of the channel or differential expression of associated proteins regulates the function of TRPV1 receptors and may thus contribute to the differences between gastric NG and DRG neurons. Such modifications 
A
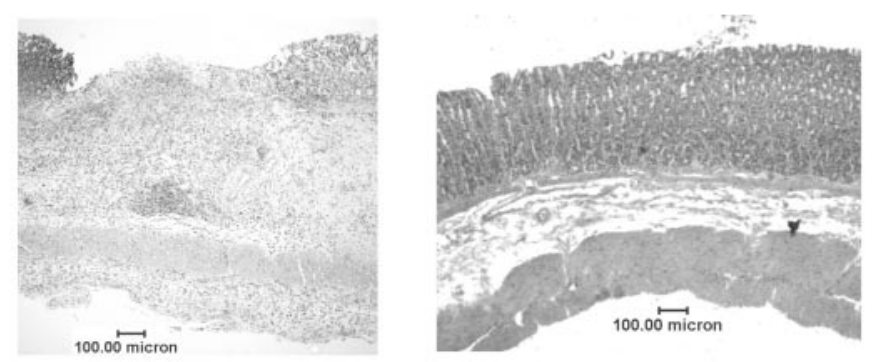

B

DRG slow
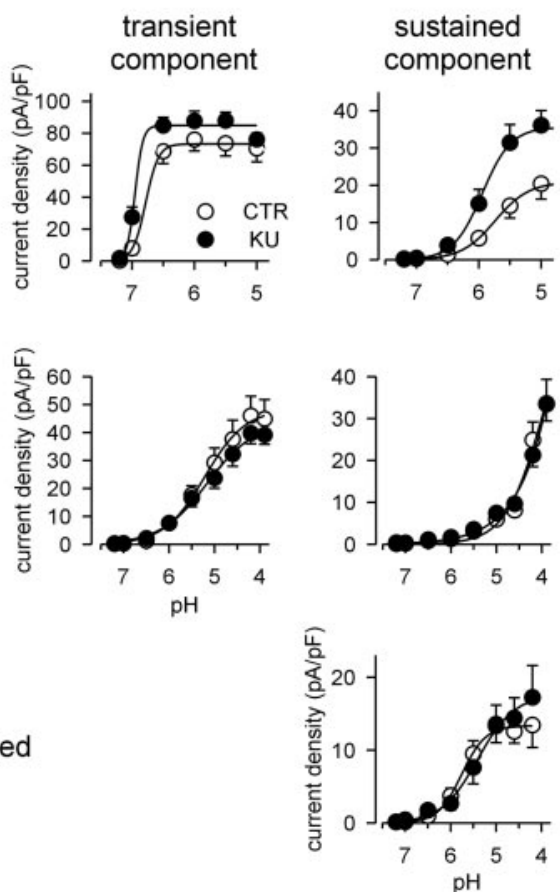

NG sustained

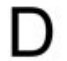

CAP-evoked current
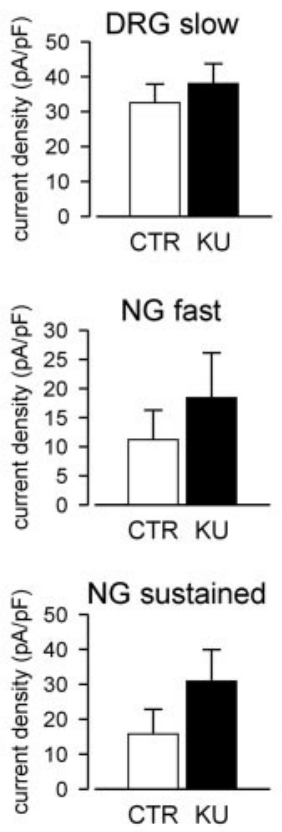

Figure 7. Effects of gastric ulceration on acid- and capsaicin-elicited currents in gastric DRG and NG neurons. $A$, Photomicrographs of the stomach $7 \mathrm{~d}$ after luminal exposure to acetic acid (left) or saline (right). $\mathrm{PH}$ concentration-response relationships for the transient (left) and sustained (right) components of the acid-elicited current in DRG (B) and NG ( $C$ neurons from control (CTR) rats and those with KUs. Current was normalized to cell capacitance. Data are reported for DRG neurons exhibiting slowly activating and desensitizing, slow-type acid-elicited currents (CTR, $n=17 ; \mathrm{KU}, n=18)(\boldsymbol{B})$ and for NG neurons exhibiting rapidly activating and desensitizing, fast-type acid-elicited currents (CTR, $n=15 ; \mathrm{KU}, n=21)$ or exhibiting only an acid-elicited sustained current (CTR, $n=18 ; \mathrm{KU}, n=14)$ (C). D, Summary of capsaicin (1 $\mu \mathrm{M})$-evoked currents in gastric DRG slow-type neurons (CTR, $n=16 ; \mathrm{KU}, n=15$ ), NG fast-type neurons (CTR, $n=5 ; \mathrm{KU}, n=7$ ), and NG sustained-type neurons (CTR, $n=14$; $\mathrm{KU}, n=9$ ). Current was normalized to cell capacitance. There was no significant effect of gastric ulceration on the amplitude of the current evoked by capsaicin in any group.

or changes in expression may also contribute to an upregulation in TRPV1 after acute mucosal injury and alter the relative importance of this channel in chemosensation.

\section{Acid-evoked currents and membrane excitability}

Ischemia and/or inflammation increases the proton concentration within the affected area, which then activates nociceptors and contributes to pain. Although ASICs are expressed in nerve terminals, the rapid current desensitization may limit responses to slow and longer-lasting pH changes (Alvarez de la Rosa et al., 2002). Moreover, protons may affect other ion channels, thereby altering membrane excitability (Daumas and Andersen, 1993). As expected, extracellular acidification shifted the threshold for action potential generation and did not trigger continuing spiking. However, cells remained responsive to additional increases in proton concentration, thus supporting recent experimental results in humans and animals that suggest a role for ASICs in chemonociception (Ugawa et al., 2002; Sluka et al., 2003). Interestingly, acidification did not decrease excitability in a subgroup of gastric NG neurons, defined by sustained, capsazepine-sensitive current responses to protons. Moreover, cells continued to generate action potentials for $>200$ ms after acid application. Considering the presence of TRPV1 immunoreactivity in vagal fibers innervating the gastric mucosa (Patterson et al., 2003), our findings further support a special role of gastric NG neurons in chemosensation.

\section{Effect of gastric inflammation on} acid-sensitive currents

Experimental ulcers trigger nocifensive responses consistent with gastric hypersensitivity (Ozaki et al., 2002; Lamb et al., 2003 b). These behavioral changes are associated with altered properties of primary afferent neurons, suggesting that peripheral mechanisms contribute to the development of gastric hypersensitivity. Because this hypersensitivity involves not just mechanical but also chemical stimuli (Lamb et al., 2003b), we examined the effects of inflammation on acid-sensitive currents in gastric sensory neurons.

Functional studies suggest that vagal but not spinal afferents are responsible for nocifensive behavior in response to intragastric acid instillation (Schuligoi et al., 1998; Lamb et al., 2003b). Approximately half of the gastric NG neurons studied here exhibited sustained acid-sensitive currents, which were attenuated by capsazepine at a $\mathrm{pH}$ as low as 5.5. Moreover, transient and sustained acid-sensitive (ASIC3like) currents in NG neurons activated at proton concentrations that were significantly lower than did gastric DRG neurons. The proton concentrations, presumably noxious, required to stimulate NG neurons innervating the stomach support growing evidence that vagal pathways are involved in chemonociception (Schuligoi et al., 1998; Michl et al., 2001; Holzer, 2002; Lamb et al., 2003b). We did not, however, detect an increase in NG acid-elicited currents after gastric ulceration except for changes in channel kinetics. This suggests that ASICs and TRPV1 in gastric NG neurons do not play a principal role in maintenance of the hypersensitivity in this ulceration model. The parallel changes in voltage-sensitive sodium and in voltage-sensitive potassium currents may explain the enhanced responses to chemical stimuli resulting from an increase in excitability (Bielefeldt et al., 2002; Dang et al., 2004).

The stomach is innervated by vagus and splanchnic nerves with cell bodies located in nodose and dorsal root ganglia, respectively. Although the majority of spinal (splanchnic) afferents terminate in the mesentery, serosa, or muscle of the stomach, vagal fibers also extend into the mucosa, bringing them into close proximity to acidic luminal contents (Patterson et al., 2003). Ray- 
Table 1. Properties of acid-sensitive currents in visceral sensory neurons and heterologous mammalian expression systems

\begin{tabular}{|c|c|c|c|}
\hline & $\mathrm{pH}_{50}$ & $\tau_{\text {desensitization }}$ & Reference \\
\hline Gastric $\mathrm{DRG}_{\text {Fast }}$ & $6.4 \pm 0.1$ & $0.21 \pm 0.05 \mathrm{~ms}$ & \\
\hline Gastric $D_{R G}$ Slow & $6.8 \pm 0.3$ & $2.79 \pm 0.31 \mathrm{~s}$ & \\
\hline Gastric $\mathrm{NG}_{\text {Fast }}$ & $5.2 \pm 0.2$ & $0.23 \pm 0.05 \mathrm{~ms}$ & \\
\hline Gastric $N_{\text {Slow }}$ & $4.1 \pm 0.4$ & $2.63 \pm 0.12 s$ & \\
\hline Cardiac DRG & 6.6 & $0.35 s$ & Sutherland et al., 2001 \\
\hline ASIC1a & $5.8-6.8$ & $0.6-4.0 s$ & Sutherland et al., 2001; Benson et al., 2002; Hesselager et al., 2004 \\
\hline ASIC1b & $6.1-6.2$ & $0.9-1.3 \mathrm{~s}$ & Benson et al., 2002; Hesselager et al., 2004 \\
\hline $\mathrm{ASIC} 2 \mathrm{a}$ & $4.5-4.9$ & $1.4-2.8 \mathrm{~s}$ & Benson et al., 2002; Hesselager et al., 2004 \\
\hline ASIC3 & $6.2-6.7$ & $0.15-0.3 s$ & Sutherland et al., 2001; Benson et al., 2002; Hesselager et al., 2004 \\
\hline ASIC1 $\mathrm{a}$ and $\mathrm{ASIC} 1 \mathrm{~b}$ & 6.0 & $1.3 \pm 0.06 \mathrm{~s}$ & Hesselager et al., 2004 \\
\hline ASIC $1 \mathrm{a}$ and $\mathrm{ASIC} 2 \mathrm{a}$ & $5.5-6.1$ & $0.4-0.6 s$ & Benson et al., 2002; Hesselager et al., 2004 \\
\hline ASIC1a and ASIC3 & $6.3-6.6$ & $0.15 s$ & Benson et al., 2002; Hesselager et al., 2004 \\
\hline ASIC2a and ASIC3 & $5.7-6.1$ & $0.19-0.26 s$ & Benson et al., 2002; Hesselager et al., 2004 \\
\hline ASIC1a, ASIC2a, and ASIC3 & $5.1-6.4$ & $0.18-0.37 \mathrm{~s}$ & Benson et al., 2002; Hesselager et al., 2004 \\
\hline
\end{tabular}

bould et al. (1992) reported that capsaicin-sensitive spinal afferents are important for protection and the healing process in gastric ulceration by modulating blood flow. Mucosal blood flow contributes to maintenance of homeostasis in the region by removing acid and toxic agents and by supplying substances important to remodeling damaged tissue. We found that gastric ulceration sensitized the acid-evoked current by increasing the peak current and sensitivity to protons in gastric DRG neurons, the majority of which are capsaicin sensitive. The increased response of ASIC1-like currents in gastric DRG neurons conceivably could contribute a protective role in response to mucosal injury. We demonstrated recently that NGF content increases within the gastric wall after induction of ulcers (Lamb et al., 2003). NGF and other mediators increase the transcription of ASICs and the expression of acid-sensitive currents in vitro (Mamet et al., 2002). Consistent with a potential role for the upregulation of ASIC expression, Yiangou et al. (2001) recently reported increased expression of ASIC3 in tissue obtained from patients with inflammatory bowel disease. We did not see significant changes in the rapidly desensitizing acid-sensitive currents that correspond to ASIC3 expression. This may be a result of species differences, regional differences in innervation (stomach vs colon), and/or the duration of inflammation (1 week vs many months). Finally, we focused on extrinsic afferent neurons, but intrinsic neurons within the gut wall make up a significant fraction of the mucosal fibers and may thus also contribute to the apparent discrepancies.

We conclude that ASICs and TRPV1 channels transduce chemical signals triggered by protons in gastric sensory neurons. The physiological and pharmacological differences in acidsensitive currents suggest that vagal and spinal afferents have distinct functions.

\section{References}

Alvarez de la Rosa D, Zhang P, Shao D, White F, Canessa CM (2002) Functional implications of the localization and activity of acid-sensitive channels in rat peripheral nervous system. Proc Natl Acad Sci USA 99:2326-2331.

Babinski K, Catarsi S, Biagini G, Seguela P (2000) Mammalian ASIC2a and ASIC3 subunits co-assemble into heteromeric proton-gated channels sensitive to $\mathrm{Gd}^{3+}$. J Biol Chem 275:28519-28525.

Baron A, Schaefer L, Lingueglia E, Champigny G, Lazdunski M (2001) $\mathrm{Zn}^{2+}$ and $\mathrm{H}^{+}$are coactivators of acid-sensing ion channels. J Biol Chem 276:35361-35367.

Baron A, Waldmann R, Lazdunski M (2002) ASIC-like, proton-activated currents in rat hippocampal neurons. J Physiol (Lond) 539:485-494.

Baumann TK, Martenson ME (2000) Extracellular protons both increase the activity and reduce the conductance of capsaicin-gated channels. J Neurosci 20:RC80(1-5).

Baumann TK, Burchiel KJ, Ingram SL, Martenson ME (1996) Responses of adult human dorsal root ganglion neurons in culture to capsaicin and low pH. Pain 65:31-38.

Benson CJ, Sutherland SP (2001) Toward an understanding of the molecules that sense myocardial ischemia. Ann NY Acad Sci 940:96-109.

Benson CJ, Eckert SP, McCleskey EW (1999) Acid-evoked currents in cardiac sensory neurons: a possible mediator of myocardial ischemic sensation. Circ Res 84:921-928.

Benson CJ, Xie J, Wemmie JA, Price MP, Henss JM, Welsh MJ, Snyder PM (2002) Heteromultimers of DEG/ENaC subunits form $\mathrm{H}^{+}$-gated channels in mouse sensory neurons. Proc Natl Acad Sci USA 99:2338-2343.

Bevan S, Yeats J (1991) Protons activate a cation conductance in a subpopulation of rat dorsal root ganglion neurones. J Physiol (Lond) 433:145-161.

Bielefeldt K (2000) Differential effects of capsaicin on rat visceral sensory neurons. Neuroscience 101:727-736.

Bielefeldt K, Ozaki N, Gebhart GF (2002) Experimental ulcers after voltagesensitive sodium currents in rat gastric sensory neurons. Gastroenterology 122:394-405.

Blackshaw LA (1989) Responses of vagal efferent fibres to stimulation of gastric mechano- and chemoreceptors in the anaesthetized ferret. J Auton Nerv Syst 27:39-45.

Caterina MJ, Schumacher MA, Tominaga M, Rosen TA, Levine JD, Julius D (1997) The capsaicin receptor: a heat-activated ion channel in the pain pathway. Nature 389:816-824.

Caterina MJ, Rosen TA, Tominaga M, Brake AJ, Julius D (1999) A capsaicin-receptor homologue with a high threshold for noxious heat. Nature 398:436-441.

Chen CC, England S, Akopian AN, Wood JN (1998) A sensory neuronspecific, proton-gated ion channel. Proc Natl Acad Sci USA 95:10240-10245.

Chu XP, Wemmie JA, Wang WZ, Zhu XM, Saugstad JA, Price MP, Simon RP, Xiong ZG (2004) Subunit-dependent high-affinity zinc inhibition of acid-sensing ion channels. J Neurosci 24:8678-8689.

Dang K, Bielefeldt K, Gebhart GF (2004) Gastric ulcers reduce A-type potassium currents in rat gastric sensory ganglion neurons. Am J Physiol Gastrointest Liver Physiol 286:G573-G579.

Daumas P, Andersen OS (1993) Proton block of brain sodium channels. Evidence for two binding sites and multiple occupancy. J Gen Physiol 101:27-43.

Del Mar LP, Cardenas CG, Scroggs RS (1996) Capsaicin preferentially affects small-diameter acutely isolated rat dorsal root ganglion cell bodies. Exp Brain Res 111:30-34.

Gebhart GF, Kuner R, Jones RCW, Bielefeldt K (2004) Visceral hypersensitivity. In: Progress in pain research and management, Vol 30, Hyperalgesia: molecular mechanisms and clinical implications (Brune K, Handwerker HO, eds), pp 87-104. Seattle: International Association for the Study of Pain.

George AA, Tsuchiyose M, Dooley CP (1991) Sensitivity of the gastric mu- 
cosa to acid and duodenal contents in patients with non-ulcer dyspepsia. Gastroenterology 101:3-6.

Gold MS, Traub RJ (2004) Cutaneous and colonic rat DRG neurons differ with respect to both baseline and PGE2-induced changes in passive and active electrophysiological properties. J Neurophysiol 91:2524-2531.

Hesselager M, Timmermann DB, Ahring PK (2004) pH dependency and desensitization kinetics of heterologously expressed combinations of acid-sensing ion channel subunits. J Biol Chem 279:11006-11015.

Holzer P (2002) Sensory neurone responses to mucosal noxae in the upper gut: relevance to mucosal integrity and gastrointestinal pain. Neurogastroenterol Motil 14:459-475.

Ichikawa H, Sugimoto T (2003) The co-expression of VR1 and VRL-1 in the rat vagal sensory ganglia. Brain Res 980:293-296.

Jordt SE, Tominaga M, Julius D (2000) Acid potentiation of the capsaicin receptor determined by a key extracellular site. Proc Natl Acad Sci USA 97:8134-8139.

Krishtal OA, Pidoplichko VI (1981) Receptor for protons in the membrane of sensory neurons. Brain Res 214:150-154.

Lamb K, Kang YM, Gebhart GF, Bielefeldt K (2003a) Nerve growth factor and gastric hyperalgesia in the rat. Neurogastroenterol Motil 15:355-361.

Lamb K, Kang YM, Gebhart GF, Bielefeldt K (2003b) Gastric inflammation triggers hypersensitivity to acid in awake rats. Gastroenterology 125:1410-1418.

Liu L, Simon SA (2000) Capsaicin, acid and heat-evoked currents in rat trigeminal ganglion neurons: relationship to functional VR1 receptors. Physiol Behav 69:363-378.

Mamet J, Baron A, Lazdunski M, Voilley N (2002) Proinflammatory mediators, stimulators of sensory neuron excitability via the expression of acid-sensing ion channels. J Neurosci 22:10662-10670.

McCleskey EW, Gold MS (1999) Ion channels of nociception. Annu Rev Physiol 61:835-856.

McColl KE (1998) Role of gastric acid in the aetiology of dyspeptic disease and dyspepsia. Baillieres Clin Gastroenterol 12:489-502.

McColl KE, Fullarton GM (1993) Duodenal ulcer pain-the role of acid and inflammation. Gut 34:1300-1302.

Michael GJ, Priestley JV (1999) Differential expression of the mRNA for the vanilloid receptor subtype 1 in cells of the adult rat dorsal root and nodose ganglia and its downregulation by axotomy. J Neurosci 19:1844-1854.

Michl T, Jocic M, Heinemann A, Schuligoi R, Holzer P (2001) Vagal afferent signaling of a gastric mucosal acid insult to medullary, pontine, thalamic, hypothalamic and limbic, but not cortical, nuclei of the rat brain. Pain 92:19-27.

Ozaki N, Bielefeldt K, Sengupta JN, Gebhart GF (2002) Models of gastric hyperalgesia in the rat. Am J Physiol 283:G666-G676.

Page AJ, Martin CM, Blackshaw LA (2002) Vagal mechanoreceptors and chemoreceptors in mouse stomach and esophagus. J Neurophysiol 87:2095-2103.

Pan HL, Longhurst JC, Eisenach JC, Chen SR (1999) Role of protons in activation of cardiac sympathetic C-fibre afferents during ischaemia in cats. J Physiol (Lond) 518:857-866.

Patterson LM, Zheng H, Ward SM, Berthoud HR (2003) Vanilloid receptor (VR1) expression in vagal afferent neurons innervating the gastrointestinal tract. Cell Tissue Res 311:277-287.

Perry MJ, Lawson SN (1998) Differences in expression of oligosaccharides, neuropeptides, carbonic anhydrase and neurofilament in rat primary afferent neurons retrogradely labelled via skin, muscle or visceral nerves. Neuroscience 85:293-310.

Ramos EG, Esplugues J, Esplugues JV (1992) Gastric acid secretory responses induced by peptone are mediated by capsaicin-sensitive sensory afferent neurons. Am J Physiol 262:G835-G839.
Raybould HE, Sternini C, Eysselein VE, Yoneda M, Holzer P (1992) Selective ablation of spinal afferent neurons containing CGRP attenuates gastric hyperemic response to acid. Peptides 13:249-254.

Schicho R, Florian W, Liebmann I, Holzer P, Lippe IT (2004) Increased expression of TRPV1 receptor in dorsal root ganglia by acid insult of the rat gastric mucosa. Eur J Neurosci 1811-1818.

Schmulson MJ, Mayer EA (1998) Gastrointestinal sensory abnormalities in functional dyspepsia. Baillieres Clin Gastroenterol 12:545-556.

Schuligoi R, Jocic M, Heinemann A, Schoninkle E, Pabst MA, Holzer P (1998) Gastric acid-evoked c-fos messenger RNA expression in rat brainstem is signaled by capsaicin-resistant vagal afferents. Gastroenterology 115:649-660.

Sekizawa SI, Ishikawa T, Sant'Ambrogio FB, Sant'Ambrogio G (1999) Vagal esophageal receptors in anesthetized dogs: mechanical and chemical responsiveness. J Appl Physiol 86:1231-1235.

Sengupta JN, Gebhart GF (1994) Gastrointestinal afferent fibers and sensation. In: Physiology of the gastrointestinal tract (Jacobsen ED, Johnson LR, Christensen J, Alpers DH, Walsh JH, eds), pp 483-519. New York: Raven.

Simren M, Vos R, Janssens J, Tack J (2003) Acid infusion enhances duodenal mechanosensitivity in healthy subjects. Am J Physiol 285:G309-G315.

Sluka KA, Price MP, Breese NM, Stucky CL, Wemmie JA, Welsh MJ (2003) Chronic hyperalgesia induced by repeated acid injections in muscle is abolished by the loss of ASIC3, but not ASIC1. Pain 106:229-239.

Steen KH, Reeh PW, Anton F, Handwerker HO (1992) Protons selectively induce lasting excitation and sensitization to mechanical stimulation of nociceptors in rat skin, in vitro. J Neurosci 12:86-95.

Su X, Wachtel RE, Gebhart GF (1999) Capsaicin sensitivity and voltagegated sodium currents in colon sensory neurons from rat dorsal root ganglia. Am J Physiol 277:G1180-G1188.

Sugiura T, Bielefeldt K, Gebhart GF (2003) Characterization of protonsensitive currents in gastric sensory neurons. Soc Neurosci Abstr 29:693.19.

Sutherland SP, Benson CJ, Adelman JP, McCleskey EW (2001) Acidsensing ion channel 3 matches the acid-gated current in cardiac ischemiasensing neurons. Proc Natl Acad Sci USA 98:711-716.

Tack J, Caenepeel P, Fischler B, Piessevaux H, Janssens J (2001) Symptoms associated with hypersensitivity to gastric distention in functional dyspepsia. Gastroenterology 121:526-535.

Tominaga M, Wada M, Masu M (2001) Potentiation of capsaicin receptor activity by metabotropic ATP receptors as a possible mechanism for ATPevoked pain and hyperalgesia. Proc Natl Acad Sci USA 98:6951-6956.

Ugawa S, Ueda T, Ishida Y, Nishigaki M, Shibata Y, Shimada S (2002) Amiloride-blockable acid-sensing ion channels are leading acid sensors expressed in human nociceptors. J Clin Invest 110:1185-1190.

Ugawa S, Yamamoto T, Ueda T, Ishida Y, Inagaki A, Nishigaki M, Shimada S (2003) Amiloride-insensitive currents of the acid-sensing ion channel-2a (ASIC2a)/ASIC2b heteromeric sour-taste receptor channel. J Neurosci 23:3616-3622.

Vyklicky L, Knotkova-Urbancova H, Vitaskova Z, Vlachova V, Kress M, Reeh PW (1998) Inflammatory mediators at acidic $\mathrm{pH}$ activate capsaicin receptors in cultured sensory neurons from newborn rats. J Neurophysiol 79:670-676.

Waldmann R, Bassilana F, de Weille J, Champigny G, Heurteaux C, Lazdunski M (1997) Molecular cloning of a noninactivating proton-gated $\mathrm{Na}^{+}$ channel specific for sensory neurons. J Biol Chem 272:20975-20978.

Yiangou Y, Facer P, Smith JA, Sangameswaran L, Eglen R, Birch R, Knowles C, Williams N, Anand P (2001) Increased acid-sensing ion channel ASIC-3 in inflamed human intestine. Eur J Gastroenterol Hepatol 13:891-896. 